\title{
Influence of litter on herbage production in the mixed prairie
}

\author{
WALTER D. WILLMS, SEAN M. MCGINN, AND JOHAN F. DORMAAR
}

\begin{abstract}
Authors are range ecologist, meteorologist, and soil scientist, respectively, Agriculture Canada Research Station, Lethbridge, Alberta, Canada TIJ 4 B1.
\end{abstract}

Abstract

Litter (dead plant material) increases production in xeric environments but the nature of this effect is uncertain. The purpose of this study was to determine the relationship between litter quantity and herbage production over a 4-year period as well as to determine the effect of repeated removal of litter on production. The study was made in a Stipa-Bouteloua-Agropyron faciation of the Mixed Prairie association, near Lethbridge, Alberta, Canada. Litter quantity was altered by mechanical removal before spring growth and the residue separated into coarse and fine components. In Experiment 1, the effect of litter on herbage production was tested by removing litter at 0 , medium, and high levels that resulted in an average residue of coarse litter of $1,171,787$, and $377 \mathrm{~kg} \mathrm{ha}^{-1}$. Coarse litter was related to an increase in herbage production $(P<0.05)$ in 3 of the 4 years studied. The effects of litter were related to the growing conditions of each year. The linear regression coefficients describing the response (herbage production related to litter) ranged from 0.114 to 0.802 with the smallest effect under either very dry or very wet conditions. In Experiment 2, litter was removed at high levels in either $0,1,2$, or 3 successive years. These treatments resulted in an average residue of coarse litter of $1,300,164,149$, and $188 \mathrm{~kg} \mathrm{ha}^{-1}$. Herbage production was not affected by removing litter for more than 1 year but plant height, tiller weight, and herbage yield of some plant species were.

Key Words: yield, Agropyron smithii, Stipa comata, Bouteloua gracilis, Stịpa víridula, Koeleria cristata, Carex spp., soil degree-days

The litter (dead plant material) component of native grasslands affects the structure and function of the plant community through its impact on the chemical and physical environment (Facelli and Pickett 1991). Litter also acts as a physical barrier to heat and water flow at the soil surface, altering the micro-environment of the plant and soil (Weaver and Rowland 1952). Litter conserves soil moisture by reducing evaporation from the soil but reduces input from rainfall by intercepting water equivalent to about twice the weight of litter (Naeth et al. 1991). Frequent litter removal stimulates production in the mesic tallgrass prairie (Weaver and Rowland 1952) but impairs production on the xeric mixed prairie (Willms et al. 1986).

Litter reduction has serious implications for grazing management since it is independent of range condition (i.e., successional stage). Range in good condition likely has more litter and the effect of its removal will be more dramatic. Since litter reduction is generally an inherent aspect of grazing, a better understanding of the relationship between litter and production is imperative. Therefore, a study was made to define the relationship between litter quantity and herbage production as well as the effects of repeated annual litter removal on productivity. To help in interpretation of these results, we also studied the effect of litter removal on soil temperature and moisture and herbage species composition.

Lethbridge Research Station Contribution 3879229.

Manuscript accepted 12 Jan. 1993.

\section{Materials and Methods}

\section{Site Description}

The study area was located at the Agriculture Canada, Animal Diseases Research Institute, near Lethbridge, Alberta. The soils are Orthic Dark-Brown Chernozems (Typic Haploboroll) and with a loamy texture. The species were characteristic of the StipaBouteloua-Agropyron faciation of the Mixed Prairie (Coupland 1961). However, porcupine grass (Stipa spartea var. curtiseta Hitchc.) is replaced by green needle grass ( $S$. viridula Trin.) as an associated species (Table 1). The climate is continental with average daily temperatures of -9.0 and $18.1^{\circ} \mathrm{C}$ in January and July, respectively. Average annual precipitation is $404 \mathrm{~mm}$ with $32 \%$ occurring in May and June (Grace and Hobbs 1986). Average pan (Class A) evaporation during the summer months is at least double, and often triple, the average precipitation while average annual wind velocity is $20.4 \mathrm{~km} \mathrm{hr}^{-1}$ (Grace and Hobbs 1986).

Four of 5 sites selected for study had been grazed by cattle until 1985 when an exclosure ( $0.5 \mathrm{ha}$ ) was constructed at each site. The exclosure at the fifth site was constructed before 1975 . The species composition among sites was similar with several exceptions (Table 1). Range condition, defined in terms of the species composition relative to that of a stable climax community (Wroe et al. 1988), was above $80 \%$ in sites B to E but only $67 \%$ in site A. Site A had more June grass (Koeleria cristata (L.) Pers.) and pasture sage (Artemisia frigida Willd.) but less wheatgrass (Agropyron spp.) and green necdle grass. Site $E$, which had the longest period of protection from grazing, had considerably less blue grama (Bouteloua gracilis (H.B.K.) I.ag.) than the others (Table 1).

\section{Experimental Procedure}

The effect of litter removal was examined in 2 experiments over a 4-year period from 1987 to 1990 . Experiment 1 was designed to estimate the relationship between litter and herbage production. Experiment 2 was designed to estimate the effect of repeated annual litter removal on production and species composition. Each experiment was repeated on 5 sites $(\mathrm{A}-\mathrm{E})$ within exclosures. The sites were distributed over an area of $6 \mathrm{~km}^{2}$ and spaced about 1 $\mathrm{km}$ apart.

\section{Experiment 1}

Residual litter treatments at each site were established in a $3 \times 3$ Latin square design representing 3 levels of litter removal in $2 \times$ 2 -m quadrats. Litter was removed at 0 , medium, or high levels using a rotary mower set at either 7 or $3-\mathrm{cm}$ cutting height for the medium and high levels, respectively, and raking cut herbage without disturbing the soil surface. Neither cutting height disturbed the crown of plants. Litter was removed before the appearance of new leaves in late winter or early spring. The treatments were repeated on the same plots in each year from 1987 to 1990 . Plant material was sampled on a different $0.25-\mathrm{m}^{2}$ subplot in each year after the growing season in late August by cutting with electric clippers at the soil surface and removing all herbage and pasture sage. The entire herbage sample, or a subsample, was hand-separated into components of current production, coarse and fine litter, and 
Table 1. Composition (\% basal area ${ }^{1}$ ) of major species and range condition within study exclosures on 5 sites.

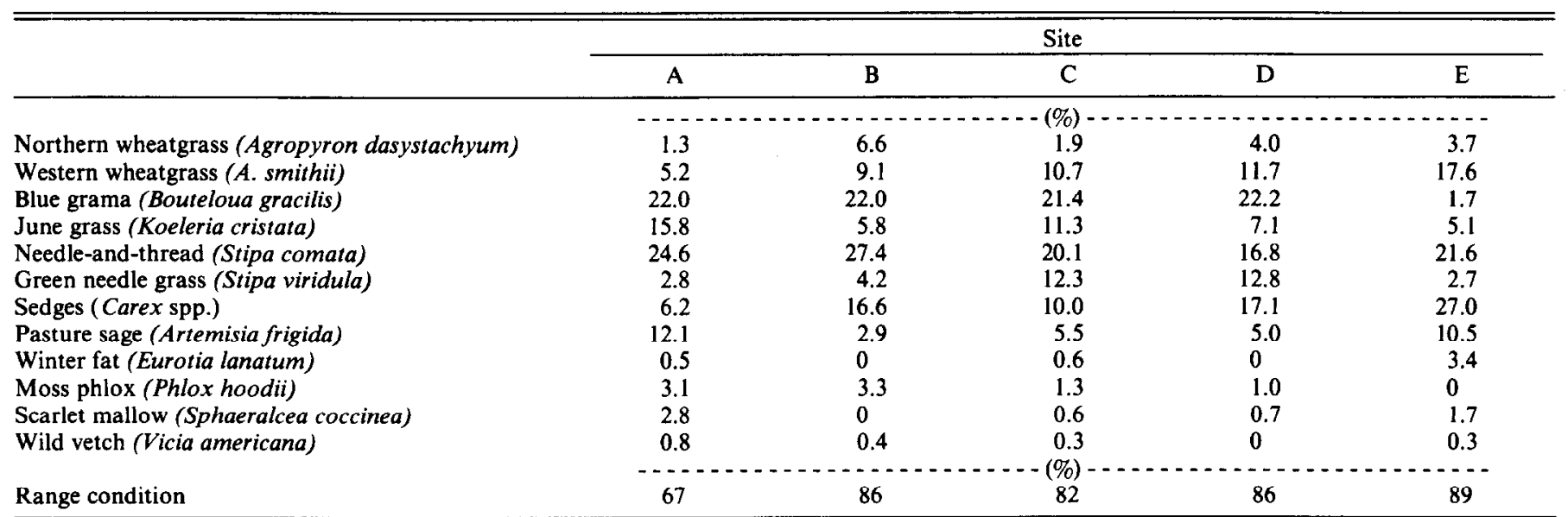

'Species composition, as a percent of basal area, was estimated by sampling 3,200 points using a 32-pin frame along a transect; only "hits" on live vegetation below 2-cm beight were counted.

pasture sage and oven-dried at $70^{\circ} \mathrm{C}$. Coarse litter, consisting of standing as well as fallen litter, was separated from fine litter using a 2-mm mesh screen. The fine litter component was ashed to account for mineral soil.

Soil temperatures were recorded at a single site using a data logger (Campbell Scientific, CR21X, Logan, Utah) fitted with thermocouples. Five thermocouples, connected in parallel $15 \mathrm{~cm}$ apart, were used to spatially average soil temperatures at $5 \mathrm{~cm}$ depth on 2 replications of each treatment. Measurements were begun in early April and continued throughout the growing season. Air temperatures at $1.5 \mathrm{~m}$ above ground were taken at 1 minute intervals and their averages output every hour. Estimates of soil moisture ( 0 to $10 \mathrm{~cm}$-depth) were made gravimetrically on all plots at intermittent times before 1990 and using time domain reflectometry (Soil Moisture Equipment Corp., Trase $6050 \mathrm{XI}$, Santa Barbara, Calif.) at bi-weekly intervals in 1990 . Soil moisture was not sampled during or immediately after a significant precipitation event.

\section{Experiment 2}

At each of the 5 sites, 4 treatments representing years of repeated annual litter removal $(0,1,2$, and 3$)$ and 4 replications were arranged in a $4 \times 4$ Latin square design with $2 \times 2$-m quadrats. Litter was removed at the same time and in a similar manner to the high removal treatment in Experiment 1. Litter was removed in 1988,1989 , and 1990 on the 3,2, and 1 repeated annual treatment, respectively. Herbage was sampled in August, 1990, by sampling tiller density, plant height (to the tip of extended leaves), and weight of dry matter for each grass species in 5 subplots $\left(100 \mathrm{~cm}^{2}\right)$ randomly located within a $0.5 \times 1.0-\mathrm{m}$ quadrat and harvesting the remainder of the herbage in a bulk sample. The bulk sample was separated into herbage components as in Experiment 1. Tiller weight was estimated as the weight of dry matter divided by tiller number.

\section{Statistical Analysis}

The relationship between litter and production (Experiment 1) was determined with regression analysis for each year, by analyzing site as a fixed factor and the quantity of fine and coarse litter as covariates; and calculating the solution for the covariates. From this analysis, it was determined that the quantity of fine litter, whether alone or in combination with coarse litter, made no contribution to production. Fine litter was, therefore, dropped from the analyses.

The effects of repeated litter removal on production and vegeta- tion characteristics (Experiment 2) were evaluated with analysis of variance for a Latin square design with multiple sites (Steel and Torrie 1980). Specific treatment means were compared using single degree of freedom contrasts. All measurements made from the subplots in Experiment 2 were transformed either by the logarithmic scale for weight data or square-root scale for tiller density in order to remove dependency between means and variances (Steel and Torrie 1980). Standard error of means for data transformed by the logarithmic scale were back-transformed using the Delta method (Rao 1973). Significant $(P<0.05)$ site $\times$ treatment interactions were evaluated by examining the treatment effect on each site. The effect of residual litter on soil moisture (Experiment 1) was analyzed for each sampling date with analysis of variance as in Experiment 2. Soil temperature at 5-cm was used to determine soil degree-days (SDD) for a $5^{\circ} \mathrm{C}$ base. Soil degree days were related to litter quantity for each year using regression analysis.

\section{Results}

\section{Experiment 1}

Precipitation over the growing season was above average in 1987 and 1989 and below average in 1988 and 1990 (Table 2). Only 59\% of average precipitation was recorded in 1988 with the greatest amount in August; that year also had the greatest pan evaporation. Although 1990 precipitation was below average, most rainfall occurred in spring when the plants' water demands are greatest.

Table 2. Precipitation and pan evaporation over a 4-year period at Lethbridge.

\begin{tabular}{|c|c|c|c|c|c|c|c|}
\hline & Jan-Mar & Apr & May & Jun & Jul & Aug & Apr-Aug \\
\hline Precipitation & \multicolumn{7}{|c|}{ 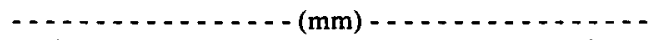 } \\
\hline 1987 & 61 & 21 & 15 & 58 & 93 & 63 & 250 \\
\hline 1988 & 34 & 0 & 22 & 45 & 12 & 63 & 142 \\
\hline 1989 & 88 & 29 & 53 & 51 & 42 & 78 & 253 \\
\hline 1990 & 42 & 38 & 76 & 40 & 33 & 36 & 223 \\
\hline \multicolumn{8}{|l|}{ Long-term } \\
\hline average & 59 & 32 & 54 & 72 & 42 & 42 & 242 \\
\hline \multicolumn{8}{|c|}{ Pan evaporation } \\
\hline 1987 & - & 215 & 247 & 304 & 242 & 169 & 1177 \\
\hline 1988 & - & 231 & 288 & 315 & 309 & 238 & 1381 \\
\hline 1989 & - & 142 & 233 & 252 & 266 & 200 & 1093 \\
\hline 1990 & - & 151 & 169 & 247 & 235 & 238 & 1040 \\
\hline Long-term & & & & & & & \\
\hline average & - & 152 & 208 & 248 & 262 & 220 & 1090 \\
\hline
\end{tabular}


Herbage production was lowest in 1988 and highest in 1990 (Table 3). Sites A and B produced about half as much forage as site E. The proportion of coarse litter in the high and medium treatments averaged 32 and $67 \%$ of the control (Table 3 ), respectively, but varied among years and sites. The amount of fine litter was not affected by the treatments.

Table 3. Herbage production and coarse litter yields (mean \pm 1 SD) summarized by year, site, and litter removal treatment in Experiment 1.

\begin{tabular}{lcc}
\hline & $\begin{array}{c}\text { Herbage } \\
\text { production }\end{array}$ & Litter \\
\hline Year & & \\
$(\mathrm{n}=15)$ & & $555 \pm 298$ \\
1987 & $688 \pm 168$ & $912 \pm 654$ \\
1988 & $200 \pm 126$ & $824 \pm 371$ \\
1989 & $854 \pm 401$ & $820 \pm 578$ \\
1990 & $1406 \pm 652$ & \\
Site & & \\
$(\mathrm{n}=12)$ & & $603 \pm 243$ \\
$\mathrm{~A}$ & $540 \pm 318$ & $590 \pm 298$ \\
$\mathrm{~B}$ & $607 \pm 455$ & $671 \pm 402$ \\
$\mathrm{C}$ & $815 \pm 519$ & $1233 \pm 784$ \\
$\mathrm{D}$ & $767 \pm 597$ & \\
E & $1230 \pm 760$ & \\
Litter removal & & \\
treatment & & $1171 \pm 614$ \\
(n=20) & & $387 \pm 237$ \\
Control & & \\
Medium & & \\
High & & \\
\hline
\end{tabular}

Herbage production was positively correlated $(P<0.05)$ with coarse litter in each year except 1989 (Table 4). Significant linear regression coefficients ranged from 0.114 in 1988 to 0.802 in 1990 . Although production generally differed among sites, the coefficients were similar as indicated by no interaction $(P<0.05)$ between site and litter quantities (Table 4).

Table 4. Effect of site and coarse litter $\left(\mathrm{g} 0.25 \mathrm{~m}^{-2}\right)$ on forage production over a 4-year period at 5 sites on a Stipa-Bouteloua-Agropyron community.

\begin{tabular}{lcccccc}
\hline & \multicolumn{4}{c}{ P $>\mathrm{F}$} & & \multicolumn{2}{c}{ Litter } \\
\cline { 2 - 4 } \cline { 6 - 7 } Year & Site & Litter & Site $\times$ litter & Intercept & Coefficient \\
\hline 1987 & $<0.001$ & $<0.001$ & 0.930 & & $15.71(1.70)^{1}$ & $0.288(0.065)$ \\
1988 & $<0.001$ & $<0.001$ & 0.319 & & $5.13(0.77)$ & $0.114(0.015)$ \\
1989 & $<0.001$ & 0.127 & 0.586 & & $31.23(4.45)$ & $0.192(0.123)$ \\
1990 & 0.56 & $<0.001$ & 0.279 & & $28.16(5.85)$ & $0.802(0.128)$ \\
\hline
\end{tabular}

IStandard error of estimate.

Soil moisture estimates in the 0 to $10 \mathrm{~cm}$ depth were similar among treatments at each sampling time except one in 1987 when soil moisture in the control, medium, and high treatments averaged 25,23 , and $22 \%$, respectively. The lowest soil moisture measurements were made in spring, 1988, during a prolonged dry period when estimates in each treatment averaged $8 \%$. In 1990, soil moisture was greater than $30 \%$ for most of May when water demand is normally high.

Soil degree day was inversely $(P<0.006)$ related to litter quantity (Table 5). However, the effect was not the same among years $(P=$ 0.015 ) with coefficients ranging from -1.796 in 1987 to -0.114 in 1990. The effect of litter was only significant $(P<0.05)$ in 1987 and 1990 but $P<0.10$ in 1988.
Table 5. Effect of coarse litter ( $\mathrm{kg} \mathrm{ha}^{-1}$ ) on soil $(5 \mathrm{~cm})$ degree-days (based on $5^{\circ} \mathrm{C}$ cumulated from 1 April to $9 \mathrm{July}$ ) in an analysis for all years combined as well as by year on a single site on a Stipa-Bouteloua. Agropyron community.

\begin{tabular}{lcclcc}
\hline & \multicolumn{2}{c}{ Effects $(\mathrm{P}>\mathrm{F})$} & & \multicolumn{2}{c}{ Litter } \\
\cline { 2 - 3 } \cline { 5 - 6 } Year & Litter & Year $\times$ litter & & Intercept & Coefficient \\
\hline 0.005 & 0.006 & 0.015 & & $1999(166)^{\prime}$ & $-0.210(0.053)$ \\
By Year & & & & & \\
1987 & 0.025 & & & $2714(31)$ & $-1.796(0.071)$ \\
1988 & 0.079 & & & $2967(88)$ & $-0.348(0.043)$ \\
1989 & 0.209 & & & $2134(183)$ & $-0.224(0.076)$ \\
1990 & 0.014 & & & $1766(7)$ & $-0.114(0.002)$ \\
\hline
\end{tabular}

iSE of estimate.

\section{Experiment 2}

Removing litter reduced the production of herbage and pasture sage but removing litter for more than 1 year had no cumulative effect (Table 6). The effect of litter removal differed among sites only in magnitude rather than trend. At each site, yields on the control ( 0 litter removal) were greater $(P<0.05)$ than between each removal treatment but yields among removal treatments were similar $(P>0.05)$. Proportional yield reduction with litter removal ranged from 0.38 on site $E$ to 0.72 on site $D$ for current production, 0.76 on site $C$ to 0.90 on site $E$ for coarse litter, and 0.61 on site $B$ to 0.82 on site $D$ for pasture sage. The yield of fine litter was not affected by the litter removal treatment (Table 6 ).

Litter removal resulted in greater $(P<0.05)$ tiller density of grasses and sedges (Carex spp.) combined, but reduced tiller weights (Table 6). Tiller weights decreased with litter removal from 1 to 3 successive years.

Litter removal reduced plant height of sedges and all grass species (Table 7) but the effect of removing litter from more than 1 year was significant $(P<0.05)$ only in western wheatgrass $(A$. smithii Rydb.), blue grama, and sedge spp. Tiller density of western wheatgrass, green needle grass, blue grama, and sedge spp. were not affected by removing litter. Tiller density of needle-and-thread ( $S$. comata Trin. + Rupr.) and June grass increased with number of years that litter was removed (Table 7). Tiller weights of all species, except green needle grass, were reduced by removing litter. Removing litter for more than 1 year had a cumulative effect on the tiller weights of needle-and-thread, blue grama, and sedge spp. The net effect of morphological changes was a significant $(P<0.05)$ reduction in weight only for western wheatgrass and sedge spp. (Table 7).

\section{Discussion}

The presence of litter had a significant positive effect on herbage production in $\mathbf{3}$ of 4 years of this study. Removing litter for more than 1 successive year had no effect on herbage yield but did influence plant height, tiller weight, and herbage yield of some plant species. The variable effects of litter among years appears to be related to the current growing conditions, with similar, small responses to removal in dry or wet conditions, as in 1988 and 1989 , respectively, and a large response in more moderate moisture conditions, as in 1990 (Table 4).

Litter appears to increase herbage production by reducing evaporation and making more water available for plant growth. Therefore, litter might be expected to be more effective in promoting plant growth when soil water is limiting. This hypothesis is supported only by circumstantial evidence rather than by direct measurements of evaporation and transpiration. For example, the low effectiveness of litter in both 1988 and 1989 appeared related to insufficient water across all treatments in 1988, and sufficient water across all treatments in 1989. The xeric conditions in 1988 were 
Table 6. Effect of successive annual litter removed on subsequent herbage components over 5 sites sampled either with macro-plots $\left(0.5 \mathrm{~m}^{2}\right)$ or sub-plots $\left(500 \mathrm{~cm}^{2}\right)$.

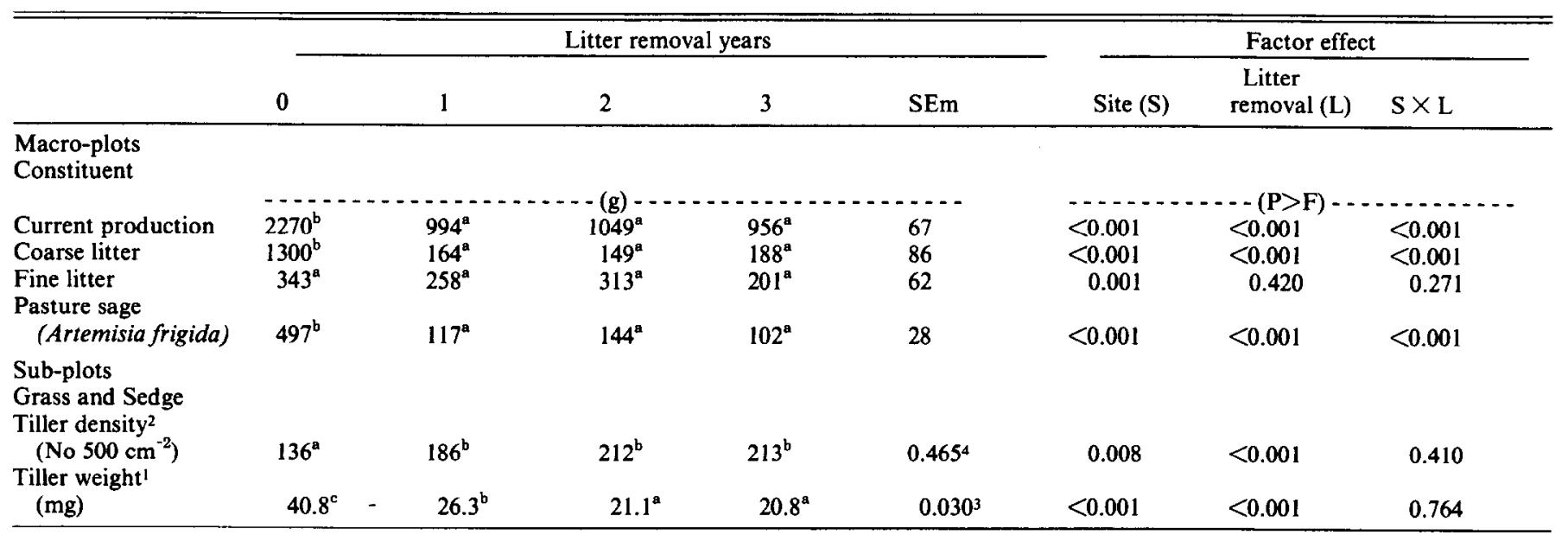

${ }^{-1}$ Means with the same letter within row do not differ $(P>0.05)$

1,2 Back-transformed means from: 'logarithmic and ${ }^{2}$ square-root transformations.

${ }^{3,4}$ Standard errors of transformed means; to estimate standard errors of back-transformed means using the Delta method (Rao 1973$)={ }^{3} S E$ of transformed means $X$ back-transformed mean; ${ }^{4} \mathrm{SE}$ of transformed means $\times 2 \times \sqrt{\text { back-transformed mean. }}$

Table 7. Species response to litter removal (means back-transformed; tiller densities from square root transformation and all others from logarithmic transformation) from 5 sites 5 .

\begin{tabular}{|c|c|c|c|c|c|c|c|}
\hline & $\begin{array}{l}\text { Litter } \\
\text { removal } \\
\text { (yrs) }\end{array}$ & $\begin{array}{l}\text { Western } \\
\text { wheatgrass }\end{array}$ & $\begin{array}{l}\text { Needle- } \\
\text { and- } \\
\text { thread }\end{array}$ & $\begin{array}{l}\text { Green } \\
\text { needle } \\
\text { grass }\end{array}$ & $\begin{array}{l}\text { June } \\
\text { grass }\end{array}$ & $\begin{array}{l}\text { Blue } \\
\text { grama }\end{array}$ & $\begin{array}{l}\text { Sedge } \\
\text { spp. }\end{array}$ \\
\hline Height 1 & $\begin{array}{l}0 \\
1 \\
2 \\
3 \\
\text { SEm }^{3}\end{array}$ & $\begin{array}{l}23.2^{\mathrm{c}} \\
16.5^{\mathrm{b}} \\
15.1^{\mathrm{ab}} \\
14.4^{\mathrm{a}} \\
0.016\end{array}$ & $\begin{array}{l}16.2^{\mathrm{b}} \\
10.1^{\mathrm{a}} \\
9.2^{\mathrm{a}} \\
9.2^{\mathrm{a}} \\
0.024\end{array}$ & $\begin{array}{c}20.5^{\mathrm{b}} \\
17.1^{\mathrm{a}} \\
17.9^{\mathrm{a}} \\
15.6^{\mathrm{a}} \\
0.017\end{array}$ & $\begin{array}{l}10.4^{\mathrm{b}} \\
7.0^{\mathrm{a}} \\
6.8^{\mathrm{a}} \\
6.5^{\mathrm{a}} \\
0.021\end{array}$ & $\begin{array}{l}8.6^{\mathrm{c}} \\
6.6^{\mathrm{b}} \\
5.5^{\mathrm{ab}} \\
4.6^{\mathrm{a}} \\
0.020\end{array}$ & $\begin{array}{l}11.2^{\mathrm{c}} \\
8.4^{\mathrm{b}} \\
7.3^{\mathrm{ab}} \\
7.1^{\mathrm{a}} \\
0.016\end{array}$ \\
\hline Tiller density ${ }^{2}$ & $\begin{array}{l}0 \\
1 \\
2 \\
3 \\
\text { SEm }\end{array}$ & $\begin{array}{c}17.7^{\mathrm{a}} \\
20.0^{\mathrm{a}} \\
13.7^{\mathrm{a}} \\
15.9^{\mathrm{a}} \\
0.36\end{array}$ & $\begin{array}{c}28.6^{\mathrm{a}} \\
43.4^{\mathrm{ab}} \\
49.0^{\mathrm{ab}} \\
67.4^{\mathrm{b}} \\
0.67\end{array}$ & $\begin{array}{c}9.5^{\mathrm{a}} \\
13.9^{\mathrm{a}} \\
10.7^{\mathrm{a}} \\
13.9^{\mathrm{a}} \\
0.39\end{array}$ & $\begin{array}{c}\left.500 \mathrm{~cm}^{-2}\right) \\
22.4^{\mathrm{a}} \\
44.6^{\mathrm{b}} \\
50.3^{\mathrm{b}} \\
45.7^{\mathrm{b}} \\
0.73\end{array}$ & $\begin{array}{c}25.3^{\mathrm{a}} \\
24.3^{\mathrm{a}} \\
34.2^{\mathrm{a}} \\
27.3^{\mathrm{a}} \\
0.61\end{array}$ & $\begin{array}{c}32.8^{\mathrm{a}} \\
26.6^{\mathrm{a}} \\
23.2^{\mathrm{a}} \\
31.1^{\mathrm{a}} \\
0.43\end{array}$ \\
\hline Tiller weight ${ }^{\prime}$ & $\begin{array}{l}0 \\
1 \\
2 \\
3 \\
\text { SEM }^{3}\end{array}$ & $\begin{array}{l}104^{\mathrm{b}} \\
62^{\mathrm{a}} \\
69^{\mathrm{a}} \\
66^{\mathrm{a}} \\
0.033\end{array}$ & $\begin{array}{l}31^{\mathrm{b}} \\
22^{\mathrm{ab}} \\
17^{\mathrm{a}} \\
17^{\mathrm{a}} \\
0.040\end{array}$ & $\begin{array}{l}61^{\mathrm{a}} \\
44^{\mathrm{a}} \\
40^{\mathrm{a}} \\
43^{\mathrm{a}} \\
0.040\end{array}$ & $\begin{array}{l}26^{\mathrm{b}} \\
17^{\mathrm{a}} \\
15^{\mathrm{a}} \\
17^{\mathrm{a}} \\
0.028\end{array}$ & $\begin{array}{l}12^{\mathrm{c}} \\
10^{\mathrm{bc}} \\
8^{\mathrm{ab}} \\
6^{\mathrm{a}} \\
0.028\end{array}$ & $\begin{array}{l}20^{\mathrm{c}} \\
16^{\mathrm{b}} \\
14^{\mathrm{ab}} \\
12^{\mathrm{a}} \\
0.022\end{array}$ \\
\hline Weight ${ }^{1}$ & $\begin{array}{l}0 \\
1 \\
2 \\
3 \\
\text { SEm }^{3}\end{array}$ & $\begin{array}{l}1.59^{\mathrm{b}} \\
1.16^{\mathrm{ab}} \\
0.81^{\mathrm{a}} \\
0.82^{\mathrm{a}} \\
0.038\end{array}$ & $\begin{array}{l}0.74^{\mathrm{a}} \\
0.90^{\mathrm{a}} \\
0.87^{\mathrm{a}} \\
1.02^{\mathrm{a}} \\
0.045\end{array}$ & $\begin{array}{l}0.52^{\mathrm{a}} \\
0.59^{\mathrm{a}} \\
0.44^{\mathrm{a}} \\
0.57^{\mathrm{a}} \\
0.038\end{array}$ & $\begin{array}{c}-2) \ldots . .40^{\mathrm{a}} \\
0.68^{\mathrm{a}} \\
0.70^{\mathrm{a}} \\
0.67^{\mathrm{a}} \\
0.038\end{array}$ & $\begin{array}{l}0.25^{\mathrm{a}} \\
0.21^{\mathrm{a}} \\
0.26^{\mathrm{a}} \\
0.17^{\mathrm{a}} \\
0.0176\end{array}$ & $\begin{array}{l}0.61^{\mathrm{b}} \\
0.39^{\mathrm{ab}} \\
0.32^{\mathrm{a}} \\
0.38^{\mathrm{a}} \\
0.022\end{array}$ \\
\hline
\end{tabular}

Means with the same letter with subset of column do not differ $(P<0.05)$

1,2 Back-transformed means from: 'logarithmic and 2square-root transformations.

${ }^{3,4}$ Standard errors of transformed means; to estimate standard errors of back-transformed means using the Delta method (Rao 1973) = ${ }^{3} S E$ of transformed means $X$ back-transformed mean; ${ }^{4} \mathrm{SE}$ of transformed means $\times 2 \times \sqrt{\text { back-transformed mean }}$

sSite $X$ treatment significant $(P<0.05)$ only for June grass $(w t$, till, tiller wt), western wheatgrass (ht), and sedges (wt) 
attributed to low precipitation in winter and spring and a high evaporation potential during the growing season. Precipitation in 1989 was almost double that of the previous year with substantially lower pan evaporation (Table 2). Litter effectiveness was reduced when water was either not available for conservation or abundant water for growth made conservation irrelevant.

The effectiveness of litter was particularly pronounced in 1990 when precipitation was below average but the rainfall events were uniformly distributed over the growing season and each event produced substantial amounts of water. Litter intercepts rainfall and reduces the amount of water available for infiltration (Naeth et al. 1991), but it also reduces surface runoff and reduces evaporation between rainfall events.

The water conservation hypothesis was not supported by soil moisture estimates between litter removal treatments but was supported by soil heating as indicated by significant $(P<0.05)$ inverse relationships between litter quantity and soil degree days (Table 5). The soil degree days reflect evaporation potential and soil moisture and, therefore, provide another index of litter effectiveness. Since soil moisture was similar among treatments over most of the year, the soil degree day is chiefly a function of litter. The relationship between soil degree day and litter quantity supports the observation that litter was least effective in 1988 and 1989 and most effective in 1987 and 1990.

After year 1, repeated removal of litter did not affect any of the herbage components. We expected the quantity of fine litter to decline with repeated removal since litter inputs were stopped while decomposition continued. Lack of an effect may have been due to an incomplete removal of each year's production, since herbage produced in any year was harvested after the following winter during which shattering losses from standing herbage occurred. An alternate explanation is that decomposition was not substantial enough to produce a significant effect over 3 years.

Production was expected to decrease with repeated litter removal as reported in a previous study (Willms et al. 1986). In that study, conducted on a more xeric mixed prairie community, grass production declined by 25 to $56 \%$ following 1 to 3 years of litter removal while in the present study production was reduced by $56 \%$ regardless of the number of times litter was removed (Table 6). Some of the differences in response between the 2 studies may be due to the composition of the plant community, since species respond differently to repeated litter removal (Table 7).

The response of some species to repeated litter removal was not expected based on their response to summer grazing. Western wheatgrass, blue grama, and sedge spp. are all "increasers" (Wroe et al. 1988) but, in most cases, responded to litter removal with significantly $(P<0.05)$ reduced plant heights and tiller weight or yield (Table 7). Shorter plant heights of all species, as a result of litter removal (Table 7), may be the consequence of reduced water available for plant growth while greater tiller density in some species may be due to increased light intensity at the crown (Willms 1988).
Litter quantity may be as important to the productivity of the mixed prairie grasslands as is range condition. Although the production response to litter or range condition is highly variable and dependent on current moisture conditions, herbage production was reduced up to $60 \%$ with litter removal, which is comparable to a reduction of about $50 \%$ in yield (Unpublished data, Adams), and $68 \%$ in recommended stocking rate (Wroe et al. 1988), for range in poor condition.

The amount of residual litter is an index of grazing pressure which, over time, will affect range condition. Blue grama is associated with reduced range condition on the study site and is favored by the warmer and drier soil environment which is created when litter is removed (Weaver and Roland 1952) and infiltration reduced (Naeth et al. 1991). On the other hand, artificially increasing litter by adding straw reduced the cover of blue grama and increased needle-and-thread (Smoliak 1965), which is associated with better range condition.

The immediate effect of litter removal due to overgrazing can be overcome by reducing grazing pressure and allowing litter to accumulate. The amount of litter necessary for maximum production is impossible to define due to its variable annual effect and its linear effect on production. This study suggests that, in the arid mixed prairie, maximum production is achieved with maximum litter quantity. Therefore, grazing must be managed to conserve litter in order to stabilize livestock production and sustain range condition.

\section{Literature Cited}

Coupland, R.T. 1961. A reconsideration of grassland classification in the Northern Great Plains of North America. J. Ecol. 49:135-167.

Facelli, J.M., and S.T.A. Pickett. 1991. Plant litter: Its dynamics and effects on plant community structure. Bot. Rev. 57:2-32.

Grace, B., and E.H. Hobbs. 1986. The climate of the Lethbridge agricultural area: 1902-1985. LRS Mimeo Report 3 (Revised), Res. Sta., Lethbridge, Alberta.

Naeth, M.A., A.W. Bailey, D.S. Chanasyk, and D.J. Pluth. 1991. Water holding capacity of litter and soil organic matter in mixed prairie and fescue grassland ecosystems of Alberta. J. Range Manage. 44:13-17.

Rao, C.R. 1973. Linear statistical inference and its applications, 2nd ed. Wiley and Sons, N.Y.

Smoliak, S. 1965. Effects of manure, straw, and inorganic fertilizers on northern great plains ranges. J. Range Manage. 18:11-14.

Steel, R.G.D., and J.H. Torrie. 1980. Principles and procedures of statistics: A biometrical approach, 2nd ed. McGraw-Hill Book Co., N.Y.

Weaver, J.E., and N.W. Rowland. 1952. Effects of natural mulch on development, yield, and structure of native grassland. Bot. Gaz. 114:1-19.

Willms, W.D. 1988. Response of rough fescue (Festuca scabrella) to light, water, temperature, and litter removal, under controlled conditions. Can. J. Bot. 66:429-434.

Willms, W.D., S. Smoliak, and A.W. Bailey. 1986. Herbage production following litter removal on Alberta native grasslands. J. Range Manage. 39:536.

Wroe, R.A., S. Smoliak, B.W. Adams, W.D. Willms, and M.L. Anderson. 1988. Guide to range condition and stocking rates for Alberta grasslands. Alberta, Forestry Lands and Wildlife Publ. Edmonton, Alberta. 